\title{
HIGH-DENSITY PLASMA-INDUCED ETCH DAMAGE OF GaN
}

\author{
R. J. Shul, L. Zhang," A. G. Baca," C. G. Willison," J. Han," S. J. Pearton," F. Ren, "J. C. \\ Zolper,"' L. F. Lester"

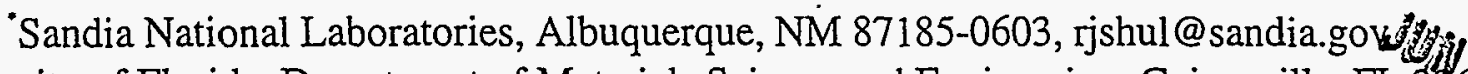 \\ "University of Florida, Department of Materials Science and Engineering, Gainesville, F \\ -.. Office of Naval Research, Arlington, VA 22217 \\ ...'University of New Mexico, Center for High Technology Materials, Albuquerque, NM 870
}

\begin{abstract}
Anisotropic, smooth etching of the group-II nitrides has been reported at relatively high rates in high-density plasma etch systems. However, such etch results are often obtained under high dc-bias and/or high plasma flux conditions where plasma induced damage can be significant. Despite the fact that the group-III nitrides have higher bonding energies than more conventional III-V compounds, plasma-induced etch damage is still a concern. Attempts to minimize such damage by reducing the ion energy or increasing the chemical activity in the plasma often result in a loss of etch rate or anisotropy which significantly limits critical dimensions and reduces the utility of the process for device applications requiring vertical etch profiles. It is therefore necessary to develop plasma etch processes which couple anisotropy for critical dimension and sidewall profile control and high etch rates with low-damage for optimum device performance. In this study we report changes in sheet resistance and contact resistance for n- and p-type GaN samples exposed to an Ar inductively coupled plasma (ICP). In general, plasma-induced damage was more sensitive to ion bombardment energies as compared to plasma flux. In addition, p$\mathrm{GaN}$ was typically more sensitive to plasma-induced damage as compared to n-GaN.
\end{abstract}

\section{INTRODUCTION}

Plasma-induced damage has become more relevant to the group-III nitride materials as interest in electronic devices has increased. For example, with the recent reports of GaN/AlGaN heterojunction bipolar transistors (HBTs) ${ }^{1-3}$ low damage etch processes are required to form the collector and base contacts. For HBTs, plasma-induced damage can increase surface recombination currents in the base-emitter junction and surface generation currents in the basecollector junction. Furthermore, the active regions of many electronic devices of interest are often shallow thus requiring low damage plasma processes to ensure optimum device performanice.

To date, the majority of plasma etch development for the group-III nitrides has been for optoelectronic devices where mesa structures are etched to depths often greater than $1 \mu \mathrm{m}$. The etch requirements typically include high rate $(\sim 1 \mu \mathrm{m} / \mathrm{min})$, smooth sidewall morphologies, and anisotropic profiles. With the increased interest in electronic devices, etch requirements must also include slow, controlled etch rates, selectivity of one material over another, and lowdamage. High-density plasma (HDP) etch systems, and in particular inductively coupled plasma (ICP) etch systems, have shown encouraging results for the development of versatile, wellcontrolled etch processes. For example, GaN etch rates ranging from $\sim 100 \AA / \mathrm{min}$ to $>1 \mu \mathrm{m} / \mathrm{min}$ have been reported in ICP etch systems with anisotropic profiles and smooth etch 
morphologies. -10 $^{-1}$ Unfortunately, the best etch results are often obtained under energetic ion bombardment and/or high plasma flux conditions which can increase plasma-induced damage.

Plasma-induced damage can take many forms causing degradation of electrical and optical properties of the device. Several damage mechanisms are summarized below. ${ }^{11-13}$

a) Energetic ion bombardment can create lattice defects or dislocations, formation of dangling bonds on the surface, or implanted etch ions. These defects often act as deep level states and produce compensation, trapping, or recombination in the material. Damage as deep as $1000 \AA$ has been reported in GaAs. ${ }^{13}$

b) The presence of hydrogen during the etch process due to either its use in the plasma chemistry, residual water vapor in the chamber, or other sources including erosion of the photoresist mask, can unintentionally passivate the dopants present in the material up to depths of several thousand angstroms.

c) Polymer deposition may occur due to the use of plasma chemistries containing $\mathrm{CH}_{x}$ radicals or reactions of photoresist masks with the plasma.

d) Non-stoichiometric surfaces may be formed due to preferential loss of one of the lattice constituents. This often occurs due to large differences in the volatility of the respective etch products, leading to enrichment of the less volatile species, or preferential sputtering of the lighter element. Non-stoichiometric depths are typically $<100 \AA$.

Since $\mathrm{GaN}$ is more chemically inert than GaAs and has higher bonding energies, it may be reasonable to use higher ion energies during the etch process with potentially less damage to the material. However, reports of plasma-induced damage of the group-III nitrides have been limited. Pearton and co-workers have reported plasma-induced damage results for InN, InGaN, and InAIN in an ECR-generated plasma where the damage increased as a function of ion flux and ion energy." Ren and coworkers also studied the effect of plasma-induced damage on the electrical characteristics of InAIN and GaN FET structures for ECR $\mathrm{BCl}_{3}, \mathrm{BCl}_{3} / \mathrm{N}_{2}$, and $\mathrm{CH}_{4} / \mathrm{H}_{2}$ plasmas. ${ }^{14}$ Several trends were observed: 1) in the presence of hydrogen, passivation of the doping in the channel layer can occur; 2) ion bombardment energies can create deep acceptor states that compensate the material; and 3) preferential loss of $\mathrm{N}$ can produce rectifying gate characteristics on etched surfaces. Ping and coworkers studied GaN Schottky diodes for Ar and $\mathrm{SiCl}_{4} \mathrm{RIE}$ plasmas and observed more damage in pure Ar plasmas and a strong dependence on dc-bias. ${ }^{15}$

In this paper we report the effect of plasma-induced-damage on $n$ - and p-type GaN by monitoring changes in the sheet resistance $\left(R_{s h}\right)$ and specific contact resistance $\left(r_{c}\right)$ of thin conducting layers under a variety of ICP plasma conditions simulating those used during device etching. Sheet resistance and specific contact resistance determined from the circular transmission line model (TLM) are used to evaluate plasma-induced damage.

\section{EXPERIMENT}

The GaN films etched in this study were grown by either metal organic chemical vapor deposition (MOCVD) ${ }^{16}$ or RF-molecular beam epitaxy (MBE). ${ }^{17}$ Both $\mathrm{n}$ - and $\mathrm{p}-\mathrm{GaN}$ were evaluated for plasma-induced damage using an ICP reactor. The $\mathrm{n}$-GaN was $\sim 1.2 \mu \mathrm{m}$ thick while the $\mathrm{p}-\mathrm{GaN}$ was $0.3 \mu \mathrm{m}$ thick and grown over a $1 \mu \mathrm{m}$ undoped $\mathrm{GaN}$ buffer layer (see Figure 1). Hall measurements were performed on these samples to determine the carrier concentration and mobility. For the MOCVD and MBE n-GaN, the electron concentrations were $8 \times 10^{17} \mathrm{~cm}^{-3}$ and $3 \times 10^{17} \mathrm{~cm}^{-3}$ and the mobility was $315 \mathrm{~cm}^{2} / \mathrm{Ns}$ and $263 \mathrm{~cm}^{2} / \mathrm{Vs}$, respectively. For the MBE p-GaN the hole concentration was $1 \times 10^{17} \mathrm{~cm}^{-3}$ and the mobility was $5 \mathrm{~cm}^{2} / \mathrm{Vs}$. 


\section{DISCLAIMER}

Portions of this document may be illegible in electronic image products. Images are produced from the best available original document. 
Ohmic contacts for circular TLM patterns were formed by metal evaporation and liftoff using standard photolithography techniques. In order to evaluate changes in sheet resistance $\left(\Delta \mathrm{R}_{\mathrm{sh}}\right)$, $\mathrm{GaN}$ samples were first metallized and then exposed to the Ar plasma. Sheet resistance was measured at the same position before and after the plasma exposure. Therefore the effect of the doping nonuniformity across the wafer was minimized. To evaluate the specific contact resistance $\left(r_{c}\right)$ as a function of the plasma conditions, the samples were initially patterned with AZ 5214 photoresist, exposed to the Ar plasma and then metallized over areas exposed to the plasma. Measurements were taken at minimum of 4 positions on each sample. The unannealed contacts were $300 \AA \mathrm{T} i$ and $2500 \AA \mathrm{Al}$ for $\mathrm{n}-\mathrm{GaN}$ and $300 \AA \mathrm{Ni}$ and $2500 \AA \mathrm{Au}$ for p-GaN.

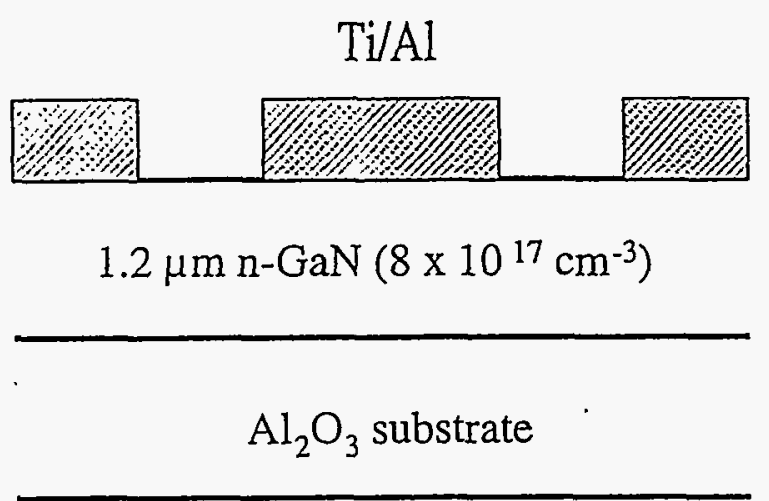

(a)

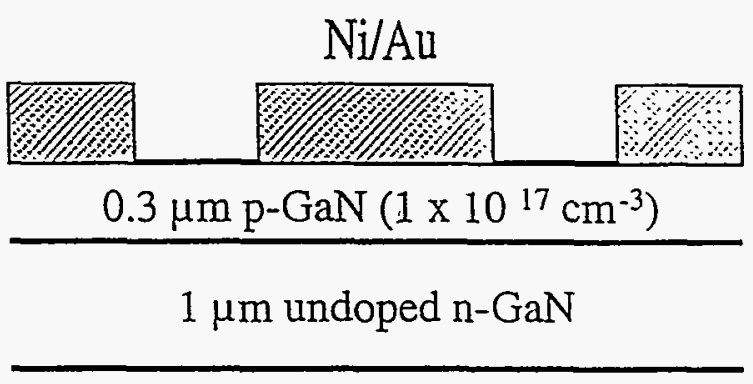

$\mathrm{Al}_{2} \mathrm{O}_{3}$ substrate

Figure 1. Schematic diagram of $\mathrm{n}$ - and $\mathrm{p}-\mathrm{GaN}$ with metal contacts in place.

The ICP reactor was a load-locked Plasma-Therm SLR 770, which used a $2 \mathrm{MHz}, 3$ turn coil ICP source. The ion energy or dc-bias was defined by superimposing a rf-bias $(13.56 \mathrm{MHz})$ on the sample. The standard ICP etch parameters used in this study were: $45 \mathrm{sccm}$ of $\mathrm{Ar}, 25^{\circ} \mathrm{C}$ electrode temperature, $2 \mathrm{mTorr}$ total pressure, $500 \mathrm{~W}$ of ICP source power, and $-100 \mathrm{~V}$ dc-bias. All samples were mounted using vacuum grease on an anodized Al carrier that was clamped to the cathode and cooled with He gas. Samples were exposed to ICP Ar plasmas for 30 seconds. Samples used to calculate etch depth were patterned using AZ 4330 photoresist. Etch depths were measured with a Dektak stylus profilometer after the photoresist was removed with an acetone spray and were consistently $<150 \AA$ independent of plasma conditions.

Plasma-etch-induced damage effects were evaluated by calculating $R_{s h}$ and $r_{c}$ with the circular transmission line-method analysis. ${ }^{18}$ Ohmic metals were deposited with gap spacings (d) of 2.5, $5,10,15,20$, and $25 \mu \mathrm{m}$ (see Figure 2). The radius of the outer metal contact $\left(r_{2}\right)$ was $100 \mu \mathrm{m}$ while the inner radius $\left(r_{1}\right)$ was defined by the radius of the outer contact minus the gap spacing for the individual structures. The resistance between contacts as a function of gap spacing was measured using a HP-4145B Semiconductor Parameter Analyzer. For.n-GaN samples, the contacts exhibited ideal ohmic I-V characteristics and the resistance was taken at an injection current of $20 \mathrm{~mA}$. However, a slightly rectified I-V curve was observed for Ni/Au contacts to $\mathrm{p}-\mathrm{GaN}$, therefore it was necessary to define the current at which the resistance was measured. Due to the relatively large $\mathrm{Mg}$ acceptor ionization energy $(\sim 170 \mathrm{meV})$, only small portions of $\mathrm{Mg}$ acceptors were ionized at room temperature and the hole concentration of $\mathrm{p}-\mathrm{GaN}$ was sensitive to 
the temperature. In order to minimize the effect of temperature variation on the measurement due to local resistive heating of each device, the resistance was measured at a fixed power of 100 $\mathrm{mW}$. The gap spacing, which was used in the analysis, was measured by SEM imaging. Linear regression of measured resistance versus spacing yielded excellent fits with correlation factors > 0.995. The data reported is the average of the measured devices.

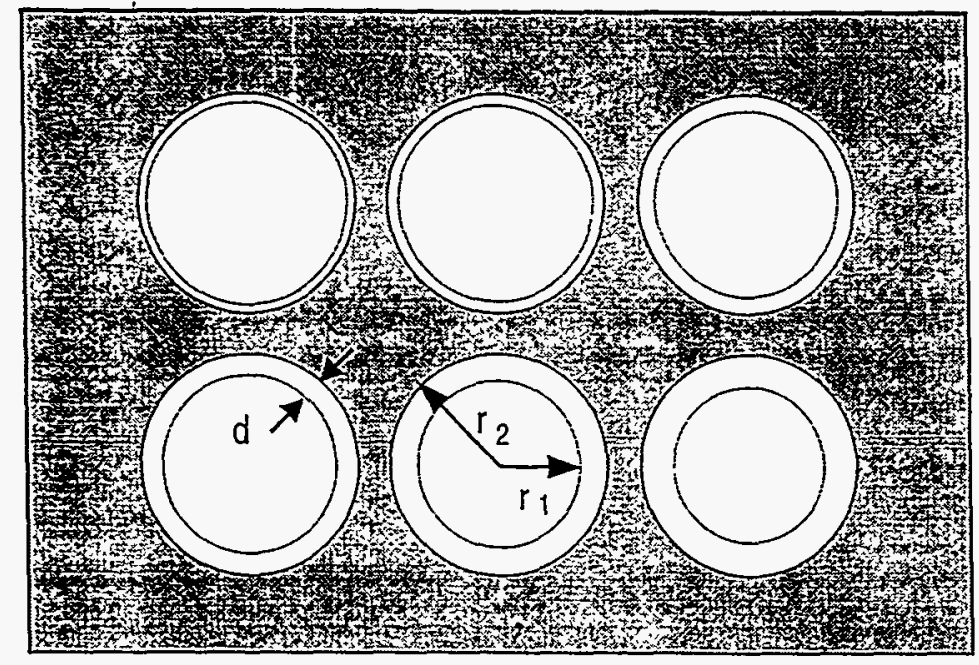

Figure 2. Schematic diagram of the circular metal contact mask used to calculate $R_{\mathrm{sh}}$ and $r_{c^{c}}$. The outer radius $r_{2}$ was held constant at $100 \mu \mathrm{m}$.

\section{RESULTS AND DISCUSSIONS}

It is important to realize that the use of a pure Ar plasma creates a worse case scenario for plasma-induced damage due to the lack of chemical interactions. With the introduction of reactive gases to the plasma for a given ion energy and plasma density, the damage will be reduced when compared to a sputter mechanism since damaged material is typically being removed at a higher rate, leaving a shallower damage depth.

Sheet resistance prior to plasma exposure $\left(\mathrm{R}_{\mathrm{sh}}\right)$, following plasma exposure, and the net change $\left(\Delta R_{s h}\right)$ are shown in Figures 3 and 4 as a function of dc-bias. The percent variation in sheet resistance $\left(\Delta R_{s h} / R_{s h}\right)$ is also displayed as a function of dc-bias. This data was obtained for MOCVD (Figure 3) and MBE (Figure 4) grown n-GaN exposed to a $30 \mathrm{sec}$ Ar ICP plasma. ICP conditions were $500 \mathrm{~W}$ ICP-source power, 2 mTorr chamber pressure, $40 \mathrm{sccm}$ Ar flow, and $25^{\circ} \mathrm{C}$ cathode temperature. As dc-bias increased, the net change in sheet resistance for both MOCVD and MBE n-GaN increased monotonically due to higher ion bombardment energies. However, the percent variation in sheet resistance was relatively low, less than $20 \%$ at $-350 \mathrm{~V}$ dc-bias. In contrast, for MBE p-GaN samples plasma-induced damage was much more sensitive to dc-bias. In Figure 5, the percent variation in sheet resistance was $-95 \%$ at $-350 \mathrm{~V}$ dc-bias. The much stronger effect of plasma-induced damage on $\mathrm{p}-\mathrm{GaN}$ was attributed to the preferential loss of lighter nitrogen atoms under energetic ion bombardment conditions, which can create ntype $\mathrm{N}$-vacancies and compensate the $\mathrm{p}-\mathrm{GaN}$. In addition, thinner $\mathrm{p}-\mathrm{GaN}$ layers $(\sim 0.3 \mu \mathrm{m}$ as compared to $\sim 1.2 \mu \mathrm{m}$ for $\mathrm{n}-\mathrm{GaN})$ and lower hole concentrations $\left(\sim 1 \times 10^{17} \mathrm{~cm}^{-3}\right.$ as compared to 3$8 \times 10^{17} \mathrm{~cm}^{-3}$ electron concentration in $\mathrm{n}-\mathrm{GaN}$ ) made the conductivity of the $\mathrm{p}-\mathrm{GaN}$ film more sensitive to the plasma-induced damages at the surface. It is worth noting that the plasma- 
induced damage did not produce a lower sheet resistance for n-GaN despite higher electron concentrations at the surface due to $\mathrm{n}$-type $\mathrm{N}$-vacancies generated by the plasma. Higher sheet resistances observed in $\mathrm{n}-\mathrm{GaN}$ at higher dc-biases may be attributed to either a thinner $\mathrm{n}$-GaN layer caused by Ar ion sputter removal (typically $<150 \AA$ ), lower electron mobility in the damaged n-GaN layer, or trapping of electrons by the plasma-induced defects.
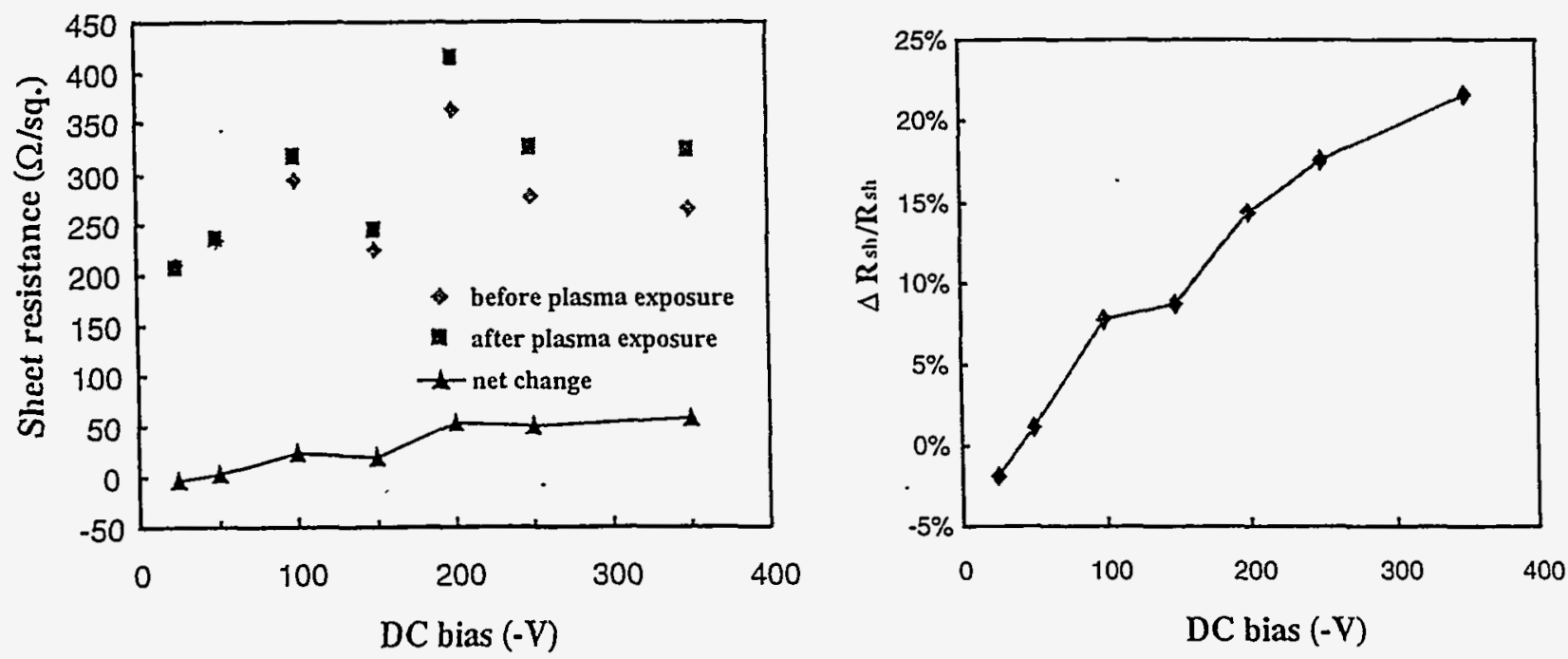

Figure 3. MOCVD $n-G a N$ sheet resistance before plasma exposure, after exposure, the net change, and the $\%$ variation $\left(\Delta \mathrm{R}_{\mathrm{sh}} / \mathrm{R}_{\mathrm{sh}}\right)$ is plotted as a function of dc-bias. ICP conditions were $500 \mathrm{~W}$ ICP-source power, $2 \mathrm{mTorr}$ chamber pressure, $40 \mathrm{sccm}$ Ar flow, and $25^{\circ} \mathrm{C}$ substrate temperature.
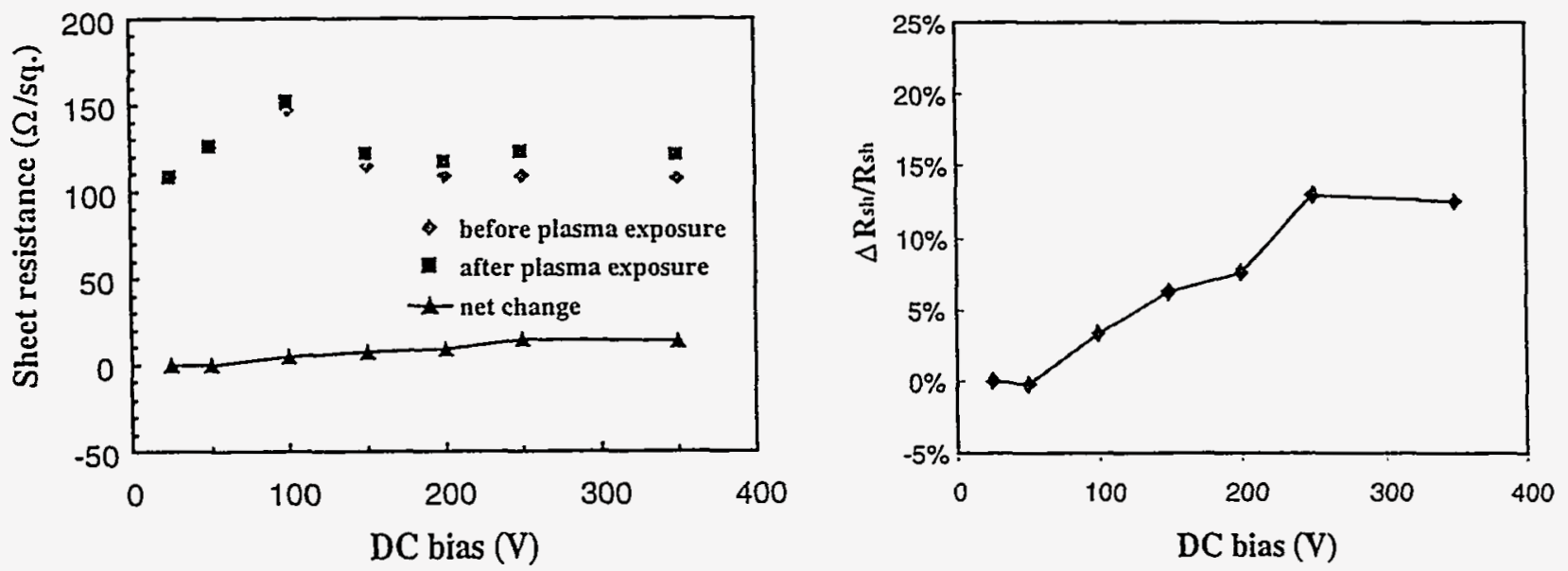

Figure 4. MBE n-GaN sheet resistance before plasma exposure, after exposure, the net change, and the \% variation $\left(\Delta R_{s h} / R_{s h}\right)$ is plotted as a function of dc-bias. ICP conditions were $500 \mathrm{~W}$ ICP-source power, 2 mTorr chamber pressure, $40 \mathrm{sccm}$ Ar flow, and $25^{\circ} \mathrm{C}$ substrate temperature.

Sheet resistance was also studied as a function of plasma flux for MOCVD and MBE $n$ - and MBE p-GaN. As a function of source power, the concentration of reactive species typically increases which increases the chemical component of the etch mechanism. In addition, the ion flux increases which increases the bond breaking efficiency and the sputter desorption component of the etch mechanism. Thus by carefully controlling the ICP-source power and the 
ion bombardment energy in the plasma, the chemical and physical components of the etch mechanism can be balanced. In Figures 6 and 7, MOCVD and MBE n-GaN sheet resistance and percent variation in sheet resistance is shown as a function of ICP-source power. Sheet resistance for $n-G a N$ samples showed a very weak dependence on ICP-source power. For these experiments, the dc-bias was held constant at $-100 \mathrm{~V}$. The percent variation in sheet resistance showed less than a 10\% change independent of plasma flux. The small amount of change in sheet resistance was attributed to the low ion bombardment energies generated at $-100 \mathrm{~V}$ dc-bias. In comparison, Figure 8 shows sheet resistance and percent variation in sheet resistance plotted as a function of ICP-source power for $\mathrm{MBE}$ grown $\mathrm{p}-\mathrm{GaN}$. Once again, the $\mathrm{p}-\mathrm{GaN}$ material was
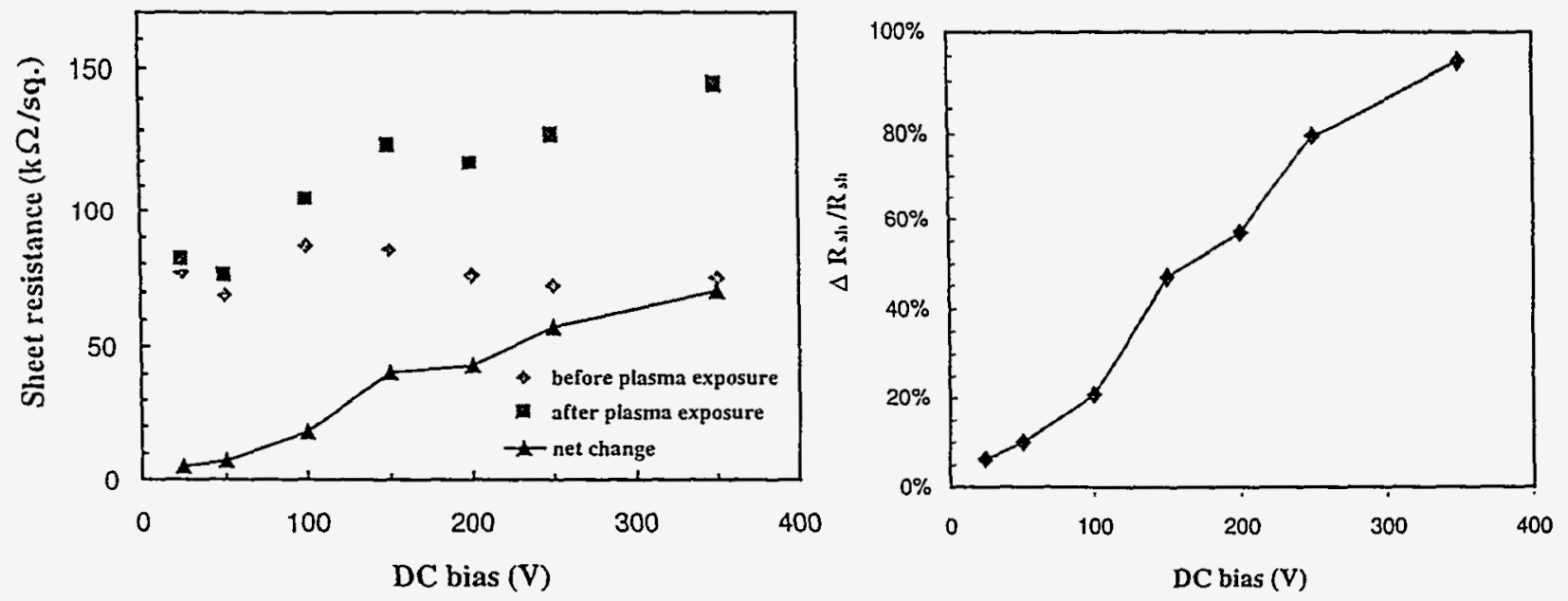

Figure 5. MBE $\mathrm{p}-\mathrm{GaN}$ sheet resistance before plasma exposure, after exposure, the net change, and the \% variation $\left(\Delta R_{s h} / R_{s h}\right)$ is plotted as a function of dc-bias. ICP conditions were $500 \mathrm{~W}$ ICP-source power, $2 \mathrm{~m}$ Torr chamber pressure, $40 \mathrm{sccm}$ Ar flow, and $25^{\circ} \mathrm{C}$ substrate temperature.
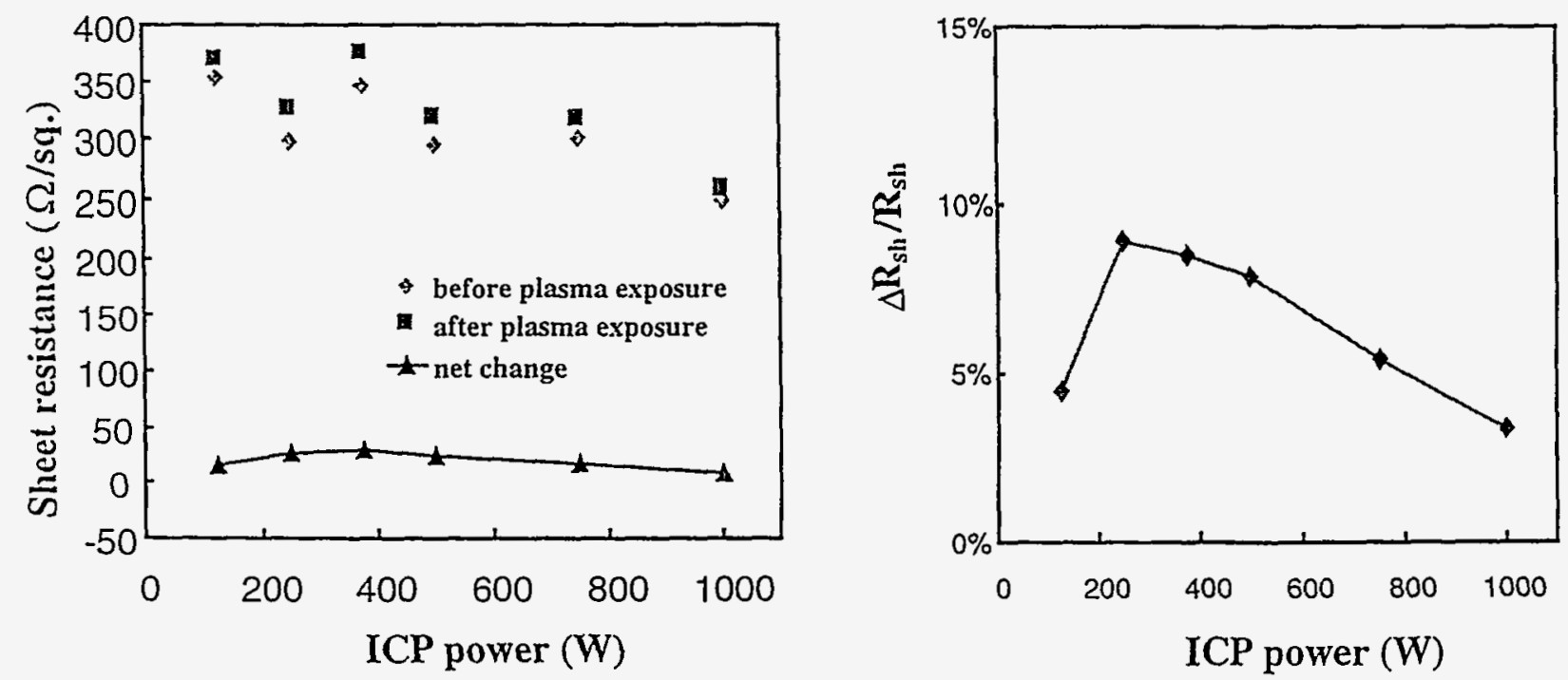

Figure 6. MOCVD $\mathrm{n}-\mathrm{GaN}$ sheet resistance before plasma exposure, after exposure, the net change, and the $\%$ variation $\left(\Delta \mathrm{R}_{\mathrm{sh}} / \mathrm{R}_{\mathrm{sh}}\right)$ is plotted as a function of ICP-source power. ICP conditions were $-100 \mathrm{~V}$ dc-bias, $2 \mathrm{mTorr}$ chamber pressure, $40 \mathrm{sccm}$ Ar flow, and $25^{\circ} \mathrm{C}$ substrate temperature. 
much more sensitive to plasma-induced damage due to preferential loss of lighter nitrogen atoms which created n-type $\mathrm{N}$-vacancies and compensated the p-GaN, thinner $\mathrm{p}-\mathrm{GaN}$ layers, and lower hole concentrations. The percent variation in sheet resistance increased to $\sim 25 \%$ at $375 \mathrm{~W}$ and then decreased as the ICP-source was increased further. This trend may be attributed to the balance between the formation and removal of the damaged layers under high plasma flux conditions. Typically, $<150 \AA$ of GaN was removed under these plasma conditions.
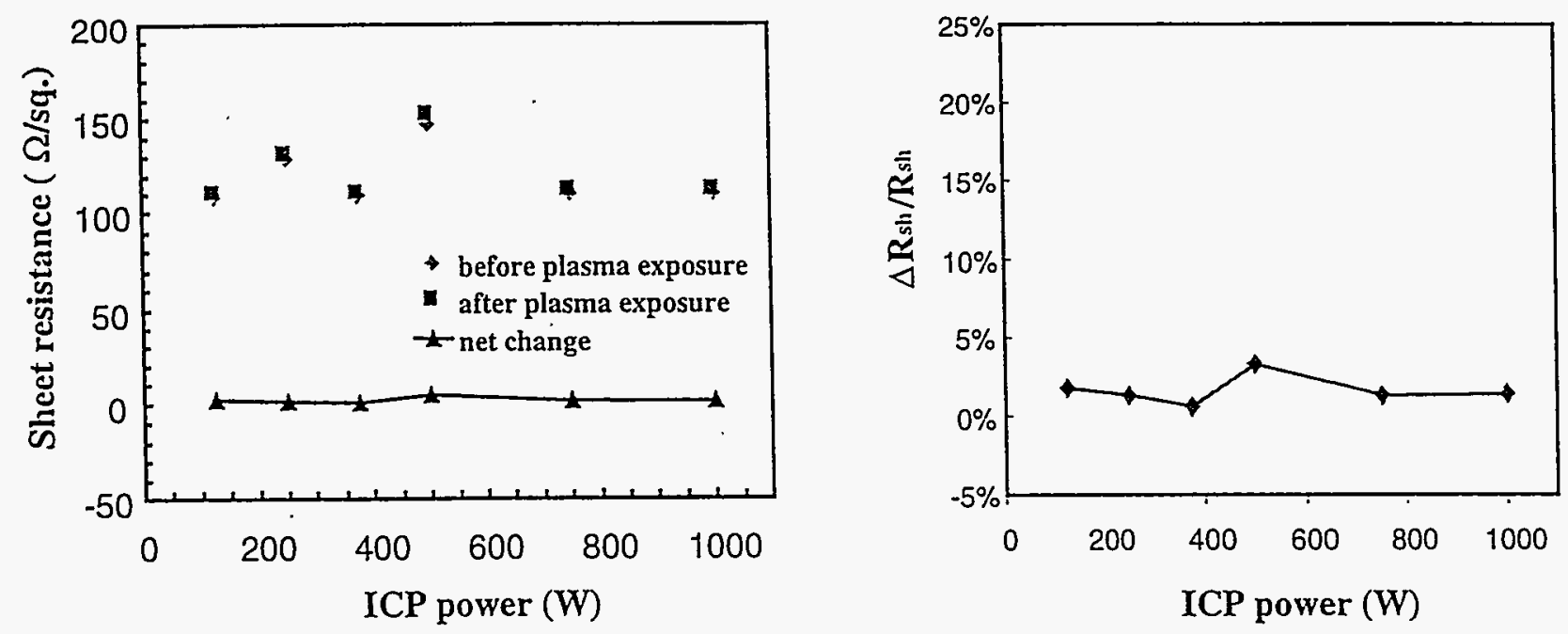

Figure 7. MBE n-GaN sheet resistance before plasma exposure, after exposure, the net change, and the $\%$ change is plotted as a function of ICP-source power. ICP conditions were $-100 \mathrm{~V}$ dcbias, 2 mTorr chamber pressure, $40 \mathrm{sccm}$ Ar flow, and $25^{\circ} \mathrm{C}$ substrate temperature.
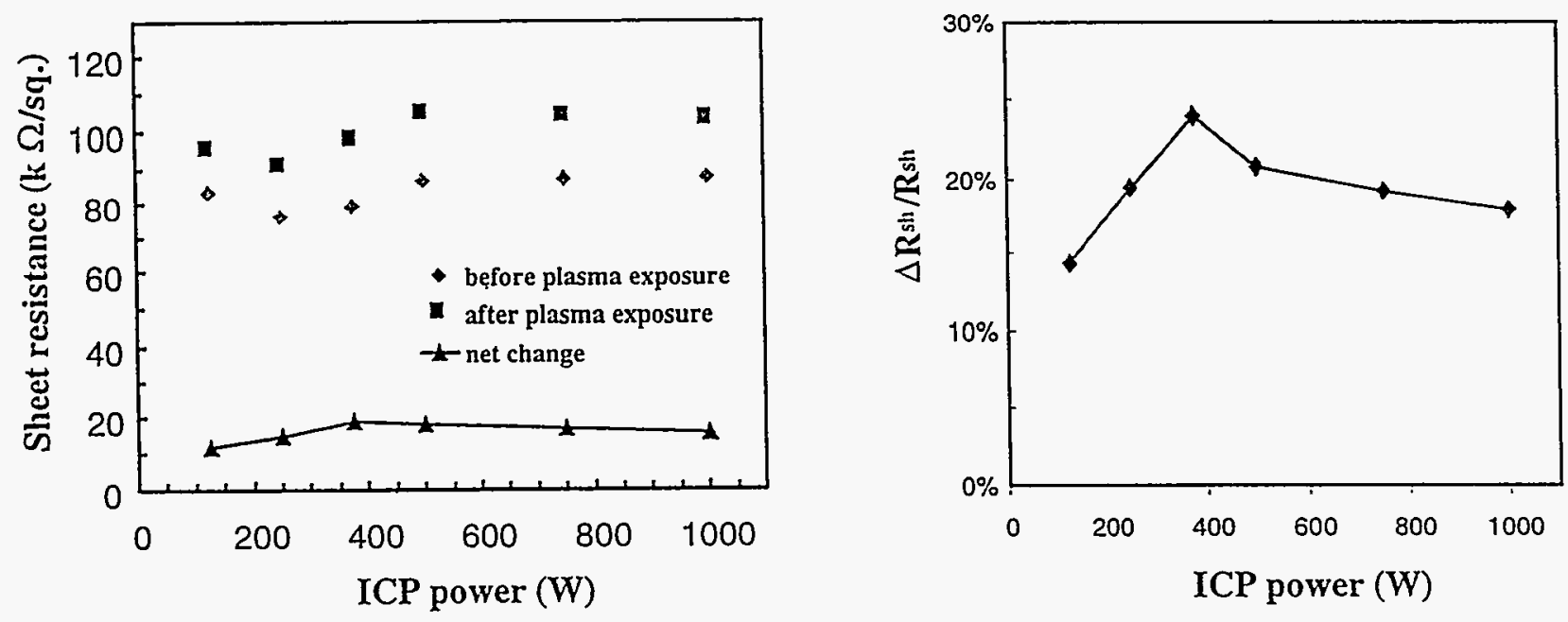

Figure 8. MBE p-GaN sheet resistance before plasma exposure, after exposure, the net change, and the \% variation $\left(\Delta \mathrm{R}_{\mathrm{sh}} / \mathrm{R}_{\mathrm{sh}}\right)$ is plotted as a function of ICP-source power. ICP conditions were $-100 \mathrm{~V}$ dc-bias, $2 \mathrm{mTorr}$ chamber pressure, $40 \mathrm{sccm}$ Ar flow, and $25^{\circ} \mathrm{C}$ substrate temperature.

Contact resistance was also used to evaluate ICP damage for MOCVD n-GaN and MBE pGaN. In Figure 9, the contact resistance is plotted as a function of dc-bias and ICP-source power for MOCVD grown $n-G a N$. The contact resistance increased by almost 3 orders of magnitude as the dc-bias increased from $-25 \mathrm{~V}$ to $-350 \mathrm{~V}$. The increase in damage was attributed to the more physical nature of the etch process under high ion bombardment energy conditions. As the ICP- 
source power increased from $125 \mathrm{~W}$ to $375 \mathrm{~W}$, the contact resistance increased by less than an order of magnitude. The dc-bias was held constant at $-100 \mathrm{~V}$. Therefore, as the plasma flux increased, the damage was less severe as compared to the more physical ion bombardment component of the etch mechanism. Above $375 \mathrm{~W}$ ICP-source power the contact resistance remained relatively constant possibly due to more effective removal of the damaged layer. Thus, the balance between the formation and removal of the damaged layers are critical to the plasmainduced damage mechanism. The contact resistance is also plotted as a function of dc-bias and ICP-source power for MBE grown p-GaN in Figure 10. Despite the fact that the contacts to p$\mathrm{GaN}$ were not Ohmic, the contact resistance for $\mathrm{p}-\mathrm{GaN}$ was again more sensitive to the increase in ion bombardment energies as compared to plasma flux.
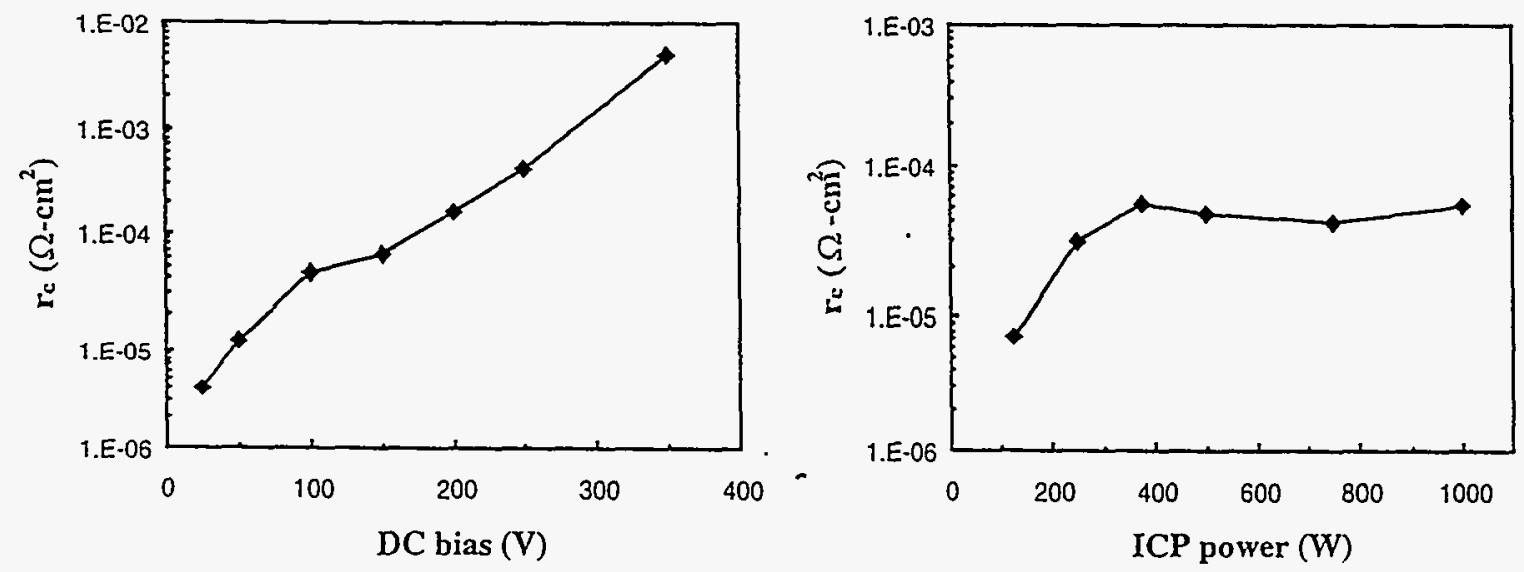

Figure 9. MOCVD n-GaN contact resistance as a function of dc-bias and ICP-source power. ICP conditions were either $500 \mathrm{~W}$ ICP-source power, or $-100 \mathrm{~V}$ dc-bias, 2 mTorr chamber pressure, $40 \mathrm{sccm}$ Ar flow, and $25^{\circ} \mathrm{C}$ substrate temperature.
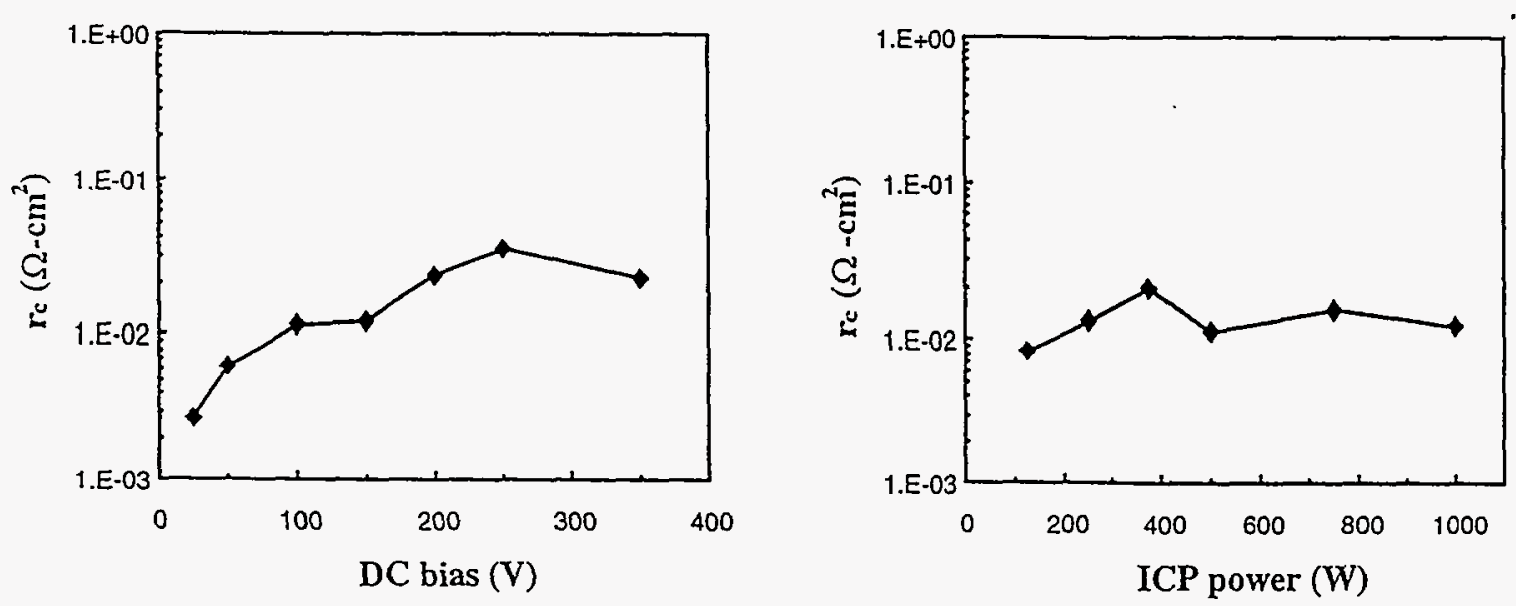

Figure 10. MBE p-GaN contact resistance as a function of dc-bias and ICP-source power. ICP conditions were either $500 \mathrm{~W}$ ICP-source power, or $-100 \mathrm{~V}$ dc-bias, $2 \mathrm{mTorr}$ chamber pressure, $40 \mathrm{sccm}$ Ar flow, and $25^{\circ} \mathrm{C}$ substrate temperature.

It is interesting to note that damage generated as a function of ICP-source power or plasma flux, showed recovery or at least stabilization under high power conditions (see Figures 6-10). This trend may demonstrate the balance between depth of the induced damage and the ability to 
remove the damaged material. Under low to moderate ICP-source powers, the damaged area was not removed efficiently. However, under high power conditions there is a competition between generation of damage and sputter removal of the damaged layers. Less than $150 \AA$ of GaN was removed under these conditions, which implies that the damage is quite shallow.

\section{CONCLUSIONS}

In summary, damage to $\mathrm{GaN}$ devices during plasma processing can be significant. Under all conditions, plasma induced damage was more sensitive to dc-bias as compared to ICP-source power implying that ion bombardment energy plays a significant role in the damage mechanism. For sheet resistance, the p-GaN samples showed much more damage than the n-GaN possibly due to the preferential loss of lighter nitrogen atoms that created n-type $\mathrm{N}$-vacancies and compensated the $\mathrm{p}-\mathrm{GaN}$. In addition, thinner $\mathrm{p}-\mathrm{GaN}$ layers and lower hole concentrations made the conductivity of $\mathrm{p}-\mathrm{GaN}$ film more sensitive to the plasma-induced damages at the surface. Higher sheet resistances observed in $\mathrm{n}-\mathrm{GaN}$ at higher dc-biases may be attributed to either a thinner n-GaN layer caused by Ar ion sputtering, lower electron mobility in the damaged n-GaN layer, or trapping of electrons by the plasma-induced defects. It is important to note that this study presents a worst case scenario since material is not being removed at rates typical in a standard etch process. Additionally, much of this damage may be removed by post-etch processes including high-temperature anneals or wet chemical etch processes.

\section{ACKNOWLEDGMENTS}

Sandia is a multiprogram laboratory operated by Sandia Corporation, a Lockheed Martin Company, for the United States Department of Energy under contract DE-ACO4-94AL85000. Two of the authors (L. F. Lester and L. Zhang) are also supported by a National Science Foundation CAREER Grant EC5-9501785. The work at the University of Florida is partially supported by a DARPA/EPRI grant (MDA 972-98-1-0006). and by NSF (DMR-9732865). 


\section{REFERENCES}

1. L. S. McCarthy, P. Kozodoy, S. P. DenBarrs, M. Rodwell, and U. K. Mishra, $25^{\text {th }}$ Int. Symp. Compound Semicond., Oct. 1998, Nara, Japan.

2. F. Ren, C. R. Abernathy, J. M. Van Hove, P. P. Chow, R. Hickman, J. J. Klassen, R. F. Kopf, H. Cho, K. B. Jung, J. R. LaRoche, R. G. Wilson, J. Han, R. J. Shul, A. G. Baca, and S. J. Pearton, MRS Internet J. Nitride Semicond. Res. $\underline{3}, 41$ (1998).

3. J. Han, A. G. Baca, R. J. Shul, C. G. Willison, L. Zhang, F. Ren, A. P. Zhang, G. T. Dang, S. M. Donovan, X. A. Cao, H. Cho, K. B. Jung, C. R. Abernathy, S. J. Pearton, and R. G. Wilson, Appl. Phys. Lett, submitted $1 / 98$.

4. S. A. Smith, C. A. Wolden, M. D. Bremser, A. D. Hanser, and R. F. Davis, Appl. Phys. Lett. 71, 3631, 1997.

5. Y. H. Lee, H. S. Kim, W. S. Kwon, G. Y. Yeom, J. W. Lee, M. C. Yoo, and T. I. Kim, J. Vac. Sci. Technol. A16, 1478 (1998).

6. Hyun Cho, J. Hong, T. Maeda, S. M. Donovan, C. R. Abernathy, S. J. Pearton, R. J. Shul, and J. Han, J. Electron. Mats. 27, 915 (1998).

7. R. J. Shul, C. G. Willison, M. M. Bridges, J. Han, J. W. Lee, S. J. Pearton, C. R. Abernathy, J. D. MacKenzie, S. M. Donovan, L. Zhang, and L. F. Lester, J. Vac. Sci. Technol A16, 1621 (1998).

8. R. J. Shul, C. G. Willison, M. M. Bridges, J. Han, J. W. Lee, S. J. Pearton, C. R. Abernathy, J. D. MacKenzie, S. M. Donovan, Mat. Res. Soc. Symp. Proc. Vol. 483, 155 (1998).

9. R. J. Shul, C. I. H. Ashby, C. G. Willison, L. Zhang, J. Han, M. M. Bridges, S. J. Pearton, J. W. Lee, and L. F. Lester, Mats. Res. Soc. Symp. Proc. 512,487 (1998).

10. R. J. Shul, L. Zhang, C. G. Willison, J. Han, S. J. Pearton, J. Hong, C. R. Abernathy, and L. F. Lester, MRS Internet J. Nitride Semicond., submitted 11/98.

11. S. J. Pearton, Appl. Surf. Sci. 117/118, 597 (1997).

12. S. J. Pearton and R. J. Shul, in Defects in Optoelectronic Materials. ed. S. W. Pang and O. Wada (Gordon and Breach, The Netherlands, in press).

13. S. W. Pang, J. Electrochem. Soc. 133, 784 (1986).

14. F. Ren, J. R. Lothian, S. J. Pearton, C. R. Abernathy, C. B. Vartuli, J. D. MacKenzie, R. G. Wilson, and R. F. Karlicek, J. Electron. Mater. 26, 1287 (1997).

15. A. T. Ping, A. C. Schmitz, I. Adesida, M. A. Khan, O. Chen, and Y. W. Yang, J. Electron. Mater. 26, 266 (1997).

16. T.-B. Ng, J. Han, R. M. Biefeld, and M. V. Weckwerth, J. Electron. Mat. 27, 190 (1998)

17. J. M. Van Hove, P. P. Chow, J. J. Klaassen, R. Hickman, A. M. Wowchak, D. R. Croswell, C. Polley, Mater. Res. Soc. Symp. Proc. 468, 51 (1997).

18. L. F. Lester, J. M. Brown, J. C. Ramer, L. Zhang, S. D. Hersee, and J. C. Zolper, Appl. Phys. Lerr 69, 2737 (1996). 